\title{
Time series modeling of the interaction between deterministic and stochastic trends
}

\author{
Imoh Udo Moffat*, Emmanuel Alphonsus Akpan
}

Department of Mathematics and Statistics, University of Uyo, Uyo, Nigeria

\section{A R T I C LE IN F O}

\section{Article history:}

Received 10 December 2016

Received in revised form

20 July 2017

Accepted 20 July 2017

\section{Keywords:}

Autocorrelation

Deterministic trend

Stochastic trend

Time series

\section{Introduction}

Statistically, the trend corresponds to sustained and systematic variations over a long period of time, and is known to be associated with the structural causes of the phenomenon under study. In most socioeconomic time series, it often dominates other components of the series. Thus, its identification has always generated problems of conceptual complexity. This problem persists because the trend (as well as other remaining components) is a latent variable, and trends in time series clearly violate the conditions of stationarity (Qi and Zhang, 2008). Therefore, certain assumptions are required to handle the different types of nonstationarity processes. Actually, a given time series being a finite realization of a stochastic process, can always be represented by one of the components or a sum of several of them (Dagum and Luati, 2001; Moffat, 2007). On the different types of nonstationarity processes, Caiado and Crato (2005) considerd a deterministic linear trend process $X_{t}=a+b_{t}+$ $\varepsilon_{t}$, where $\varepsilon_{t}$ is a white noise term that can be transformed into a stationary process by subtracting the trend $a+b_{t}$, and a stochastic linear trend process such as the random walk model (1-B) $X_{t}=\varepsilon_{t}$ or $X_{t}=$ $X_{\mathrm{t}-1}+\varepsilon_{t}$. In particular, it is useful to distinguish between a random walk plus drift (unit root process) $X_{t}=\mu+X_{t-1}+\varepsilon_{t}$ and a deterministic trend in the form $X_{t}=a+\mu_{t}+\varepsilon_{t}$. In most cases, two of the simplest versions are (Eqs. 1 and 2):

\footnotetext{
* Corresponding Author.

Email Address: moffitto@yahoo.com (I. U. Moffat) https://doi.org/10.21833/ijaas.2017.09.012

2313-626X/C) 2017 The Authors. Published by IASE.

This is an open access article under the CC BY-NC-ND license

(http://creativecommons.org/licenses/by-nc-nd/4.0/)
}

Deterministic trend (DT):

$X_{t}=b_{t}+\varepsilon_{t}$

Stochastic trend (ST):

$X_{t}=b_{t}+X_{t-1}+\varepsilon_{t}$

where $\varepsilon_{t}$ is a white noise with variance, $\sigma^{2}=1$, and $X_{0}$ $=0$. Obviously (Eqs. 3 and 4 ),

$E_{D S}\left(X_{t}\right)=E_{S T}\left(X_{t}\right)=b_{t}$

but

$V_{D S}\left(X_{t}\right)=1$ and $V_{S T}\left(X_{t}\right)=t$.

Also, the expectation with respect to all information up to time $t$ is zero.

As captured by Hamilton (1994), the stylized trend-cycle decomposition of time series $\left(X_{t}\right)$ is as follows (Eq. 5):

$X_{t}=D T_{t}+Z_{t}$

$D T_{t}=k+\delta t$

$Z_{t}=\varphi_{1} Z_{t-1}+\cdots+\varphi_{p} Z_{t-p}+\varepsilon_{t}, \varepsilon_{t} \sim W N\left(0, \sigma^{2}\right)$

where $D T_{t}$ is a deterministic trend and $Z_{t}$ is an $\operatorname{AR}(\mathrm{p})$ process. If $|\varphi|<1$, then $Y_{t}$ is $\mathrm{I}(0)$ about the deterministic trend $D T_{t}$. If $=1$, then $Z_{t}=\varphi_{1} Z_{t-1}+$ $\cdots+\varphi_{p} Z_{t-p}+\varepsilon_{t}=Z_{0}+\sum_{j=1}^{t} \varepsilon_{j}$, a stochastic trend and $X_{t}$ is I (1) with drift.

However, to avoid the complexity of the problem posed by a statistically vague definition, some researchers have resorted to two simple solutions: One consists of estimating the combined trend-cycle component; the other consists of defining the trend 
in terms of the series length (Dagum and Dagum, 2006).

Generally, trend analysis in time series is of paramount interest to researchers since it provides information about the underlying properties of the series. Fuller (2009) opines that one of the reasons for estimating the trend function is to investigate the underlying properties of the time series. Wei (2006) identifies two classes of such properties to include the deterministic trend where the mean level of the process at time $t$ is a pure deterministic function of time, and the stochastic trend where the mean level of the process changes through time randomly (Hamilton, 1994; Watson, 1986; Nelson and Plosser, 1982; Cryer and Chan, 2008). Although most macroeconomic time series are highly trended, it is difficult to determine whether the trend is deterministic or stochastic.

In our study, we consider a scenario where both the deterministic and stochastic trends coexist in a single realization.

\section{Methodology}

\subsection{Augmented dickey-fuller test}

Dickey and Fuller (1979) introduced DickeyFuller (DF) test statistic to examine the existence of unit root in a time series with an assumption that the underlying process follows the AR model. Also, Said and Dickey (1984) augment the basic autoregressive unit root test to accommodate the general ARMA (p, q) models and this test is called the Augmented Dickey-Fuller (ADF) test. Let the series be denoted by $X_{t}$ using the regression (Eq. 6)

$X_{t}=c_{t}+\beta X_{t-1}+\sum_{i=1}^{p-1} \varphi_{i} \Delta X_{t-i}+e_{t}$

where $c_{t}$ is a deterministic function of the time index $t$ and $\Delta X_{j}=X_{j}-X_{j-1}$ is the differenced series of $X_{t}$. Under the null hypothesis, $X_{t}$ is I (1) which implies that $\beta=1$. The ADF $t$-statistic based on least squares estimates of Eq. 6 is given by ADF-test $=\frac{\widehat{\beta}-1}{\operatorname{SE}(\widehat{\beta})}$.

\section{Data analysis and discussion}

Over the years, modeling internally generated revenue of a system has been of critical concern to all parties involved due to the variables of interest. In order to model the trend of the series, we examine the sequence plot in Fig. 1. From our observation, the plot appeared to contain a trend component.

Since our interest is in providing the justification for detecting between deterministic and stochastic trends, we carry out a statistical test to detect whether the trend component is deterministic or stochastic or both, using Augmented Dickey - Fuller test (ADF). We apply the ADF to the regression model that contains both intercept and trend component. The trend is said to be deterministic if the series is stationary with trend, otherwise it is stochastic. According to Table 1, the ADF test statistic value is -5.4546 and the test critical values are $-4.1213,-3.4878$, and -3.1723 at $1 \%, 5 \%$ and $10 \%$ levels of significance, respectively. Since the $\mathrm{ADF}$ test statistic is greater than all the critical values in absolute value, the null hypothesis $\left(X_{t}\right.$ is nonstationary and the trend component is not significant) is rejected with the decision that the series is stationary with a deterministic trend.

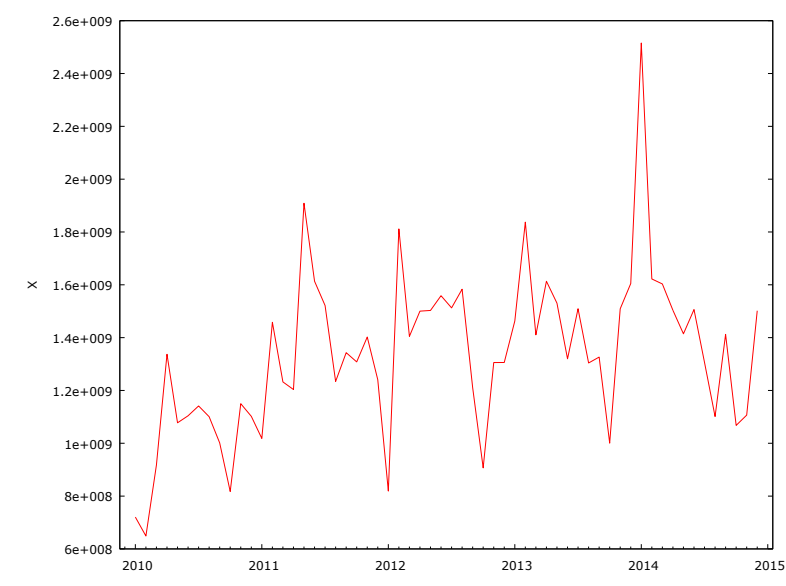

Fig. 1: Sequence plot of internally generated revenue

\begin{tabular}{|c|c|c|c|}
\hline \multirow{2}{*}{\multicolumn{2}{|c|}{$\begin{array}{c}\text { Augmented Dickey-Fuller test } \\
\text { statistic }\end{array}$}} & t-Statistic & Prob.* \\
\hline & & -5.454627 & 0.0002 \\
\hline \multirow{3}{*}{$\begin{array}{l}\text { Test critical } \\
\text { values: }\end{array}$} & $1 \%$ level & -4.121303 & \\
\hline & $5 \%$ level & -3.487845 & \\
\hline & $10 \%$ level & -3.172314 & \\
\hline
\end{tabular}

\subsection{Deterministic trend model}

The fitted trend model is presented in Eq. 7 (Excerpts from Table 2):

$X_{t}=1.1108 e+09+7.3613 e+06$

Trend

$\begin{array}{lcc}\text { s.e } & 7.4399 e+07 & 2.1212 e+06 \\ \text { t-ratio } & 14.9296 & 3.4703 \\ \text { p-value } & <0.0001 & 0.0010\end{array}$

From the deterministic trend model in Eq. 7, it is observed that the time trend in the model is significant since the $p$ - value $=0.0010<0.05$ level of significance. But the diagnostic checking of the deterministic trend model indicates that the model is not adequate since the ACF of the residuals of the deterministic trend model (Fig. 2) is auto correlated which is a clear indication of randomness in $X_{t}$. The fact that randomness exists in the residuals of the deterministic model shows that $X_{t}$ also exhibits a stochastic trend. Hence, the deterministic trend model needs to be refined to contain an ARMA process.

Again, we examine the ACF and the PACF of the residuals of deterministic trend model (Fig. 2), and 
they indicate tentatively that deterministic trend with ARMA (1, 0), ARMA $(0,1)$ and ARMA $(1,1)$ models respectively could be appropriate.
Comparing their information criteria as appeared in Tables 3, 4, and 5, we observed that deterministic trend with ARMA $(1,0)$ model has the smallest information criteria.

Table 2: Output of deterministic trend

\begin{tabular}{|c|c|c|c|c|c|}
\hline \multicolumn{6}{|c|}{$\begin{array}{c}\text { Model 1: OLS, using observations 2010:01-2014:12 }(\mathrm{T}=60) \\
\text { Dependent variable: } \mathrm{X}\end{array}$} \\
\hline & Coefficient & Std. Error & t-ratio & p-value & \\
\hline Const. & $1.11075 \mathrm{e}+09$ & $7.4399 e+07$ & 14.9296 & $<0.0001$ & $* * *$ \\
\hline Time & $7.36129 \mathrm{e}+06$ & $2.12122 \mathrm{e}+06$ & 3.4703 & 0.0010 & $* * *$ \\
\hline Mean dependent var & \multicolumn{2}{|c|}{$1.34 \mathrm{e}+09$} & S.D. dependent var & \multicolumn{2}{|c|}{$3.10 \mathrm{e}+08$} \\
\hline Sum squared resid & \multicolumn{2}{|c|}{$4.70 \mathrm{e}+18$} & S.E. of regression & \multicolumn{2}{|c|}{$2.85 e+08$} \\
\hline R-squared & \multicolumn{2}{|c|}{0.171938} & Adjusted R-squared & \multicolumn{2}{|c|}{0.157661} \\
\hline$F(1,58)$ & \multicolumn{2}{|c|}{12.04310} & P-value(F) & \multicolumn{2}{|c|}{0.000988} \\
\hline Log-likelihood & \multicolumn{2}{|c|}{-1252.105} & Akaike criterion & \multicolumn{2}{|c|}{2508.209} \\
\hline Schwarz criterion & \multicolumn{2}{|c|}{2512.398} & Hannan-Quinn & \multicolumn{2}{|c|}{2509.848} \\
\hline Rho & \multicolumn{2}{|c|}{0.324102} & Durbin-Watson & \multicolumn{2}{|c|}{1.317962} \\
\hline
\end{tabular}
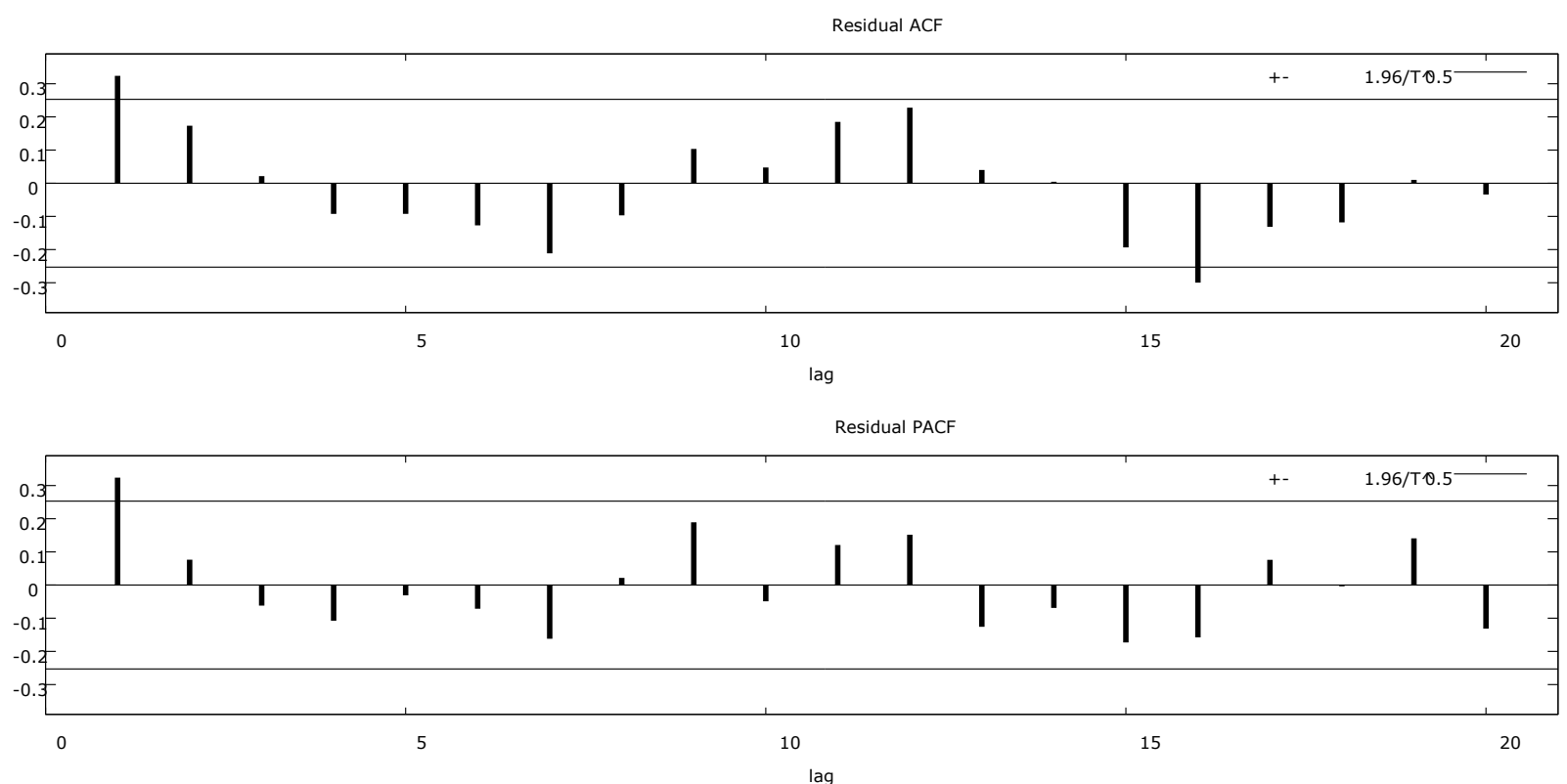

Fig. 2: ACF and PACF of the residuals from deterministic trend model

Therefore, our chosen model is the deterministic trend with ARMA $(1,0)$ model. The estimated model is presented in Eq. 8 (Excerpts from Table 3):

$$
\begin{aligned}
& X_{t}=1.1062 \mathrm{e}+09+7.6421 e+06 \text { Trend }+ \\
& 0.3304 X_{t-1} \\
& \text { s.e } \quad 9.8791 \mathrm{e}+07 \quad 2.8738 \mathrm{e}+06 \quad 0.1228 \\
& \begin{array}{llll}
\mathrm{z} \text { - ratio } & 11.1974 & 2.6592 & 2.6897
\end{array} \\
& \mathrm{p} \text {-value } \quad<0.0001 \quad 0.0078 \quad 0.0072
\end{aligned}
$$

From Eq. 8, it is observed that both trend and the ARMA $(1,0)$ processes are significant since their respective $\mathrm{p}-$ values are less than 0.05 level of significance.

The diagnostic checking of the model in Eq. 8 reveals that the residuals are no more auto

\begin{tabular}{|c|c|c|c|c|c|}
\hline \multicolumn{6}{|c|}{$\begin{array}{c}\text { Model 1: ARMAX, using observations 2010:01-2014:12 }(\mathrm{T}=60) ; \text { Dependent variable: } \mathrm{X} \\
\text { Standard errors based on Hessian }\end{array}$} \\
\hline & Coefficient & Std. Error & $\mathrm{Z}$ & p-value & \\
\hline Const & $1.1062 \mathrm{e}+09$ & $9.87911 \mathrm{e}+07$ & 11.1974 & $<0.0001$ & $* * *$ \\
\hline phi_1 & 0.330366 & 0.122826 & 2.6897 & 0.0072 & $* * *$ \\
\hline TREND & $7.64207 e+06$ & $2.87381 \mathrm{e}+06$ & 2.6592 & 0.0078 & $* * *$ \\
\hline Mean dependent var & \multicolumn{2}{|c|}{$1.34 \mathrm{e}+09$} & S.D. dependent var & \multicolumn{2}{|c|}{$3.10 \mathrm{e}+08$} \\
\hline Mean of innovations & \multicolumn{2}{|c|}{2123045} & S.D. of innovations & \multicolumn{2}{|c|}{$2.64 \mathrm{e}+08$} \\
\hline Log-likelihood & \multicolumn{2}{|c|}{-1248.706} & Akaike criterion & \multicolumn{2}{|c|}{2505.411} \\
\hline Schwarz criterion & \multicolumn{2}{|c|}{2513.789} & Hannan-Quinn & \multicolumn{2}{|c|}{2508.688} \\
\hline
\end{tabular}
correlated (Fig. 3). The implication is that both deterministic and stochastic trend coexist in the time series $X_{t}$.

Table 3: Output of deterministic trend with ARMA $(1,0)$ model

\section{Conclusion}

According to Rao (2010), deterministic trends are useful in unit root tests and in the estimation of the models with cointegration techniques. The implication of allowing for such trends is that if the model is shocked, after some departures from the trend, the variables will return to their trend values. 
On the other hand, models with stochastic trend (structural time series models) are useful in some instances. Firstly, it may be hard to identify multiple structural breaks in the deterministic trend when the sample size is small. Secondly, implementing endogenous multiple structural break tests remains a demanding exercise. Thirdly, standard classical methods of estimation can be used to estimate the effects of additional explanatory variables in structural time series models. Finally, Harvey (1985) points out that the stochastic and deterministic trend hypotheses are nested within the structural time series approach and can be evaluated with estimated values of the hyper parameters, although the power of this test is not known.

Table 4: Output of deterministic trend with ARMA $(0,1)$ model

\begin{tabular}{cccccc}
\hline \multicolumn{7}{c}{ Model 3: ARMAX, using observations 2010:01-2014:12 (T = 60) } \\
\multicolumn{7}{c}{ Dependent variable: X } \\
Standard errors based on Hessian \\
\hline \multicolumn{7}{c}{ Coefficient } & Std. Error & $\mathrm{Z}$ & $\mathrm{p}$-value & $*$ ( $)$ \\
Const & $1.1128 \mathrm{e}+09$ & $8.55138 \mathrm{e}+07$ & 13.0131 & $<0.0001$ & $* * 0158$ \\
theta_1 & 0.264255 & 0.109452 & 2.4144 & 0.0158 \\
TREND & $7.50316 \mathrm{e}+06$ & $2.49545 \mathrm{e}+06$ & 3.0067 & 0.0026 & $* * *$ \\
\hline Mean dependent var & $1.34 \mathrm{e}+09$ & S.D. dependent var & $3.10 \mathrm{e}+08$ \\
Mean of innovations & 901967.2 & S.D. of innovations & $2.67 \mathrm{e}+08$ \\
Log-likelihood & -1249.444 & Akaike criterion & 2506.887 \\
Schwarz criterion & 2515.264 & Hannan-Quinn & 2510.164 \\
\hline
\end{tabular}

Table 5: Output of deterministic trend with ARMA $(1,1)$ model Model 2: ARMAX, using observations 2010:01-2014:12 ( $\mathrm{T}=60)$

Dependent variable: $\mathrm{X}$

Standard errors based on Hessian

\begin{tabular}{cccccc}
\hline \multicolumn{2}{c}{ Coefficient } & Std. Error & $\mathrm{Z}$ & $\mathrm{p}$-value & \\
Const & $1.10134 \mathrm{e}+09$ & $1.06576 \mathrm{e}+08$ & 10.3339 & $<0.0001$ & $* * *$ \\
phi_1 & 0.496663 & 0.268404 & 1.8504 & 0.0643 & $*$ \\
theta_1 & -0.181411 & 0.286809 & -0.6325 & 0.5271 & $* *$ \\
TREND & $7.71014 \mathrm{e}+06$ & $3.08148 \mathrm{e}+06$ & 2.5021 & 0.0123 & $* 3.10 \mathrm{e}+08$ \\
Mean dependent var & $1.34 \mathrm{e}+09$ & S.D. dependent var & $2.63 \mathrm{e}+08$ \\
Mean of innovations & 3182619 & S.D. of innovations & 2507.062 \\
Log-likelihood & -1248.531 & Akaike criterion & 2511.158 \\
Schwarz criterion & 2517.534 & Hannan-Quinn & Akaike criterion & 2507.062 \\
Log likelihood & -1248.531 & Hannan Quinn & 2511.158 \\
\hline Schwarz criterion & 2517.534 & &
\end{tabular}

Residual ACF
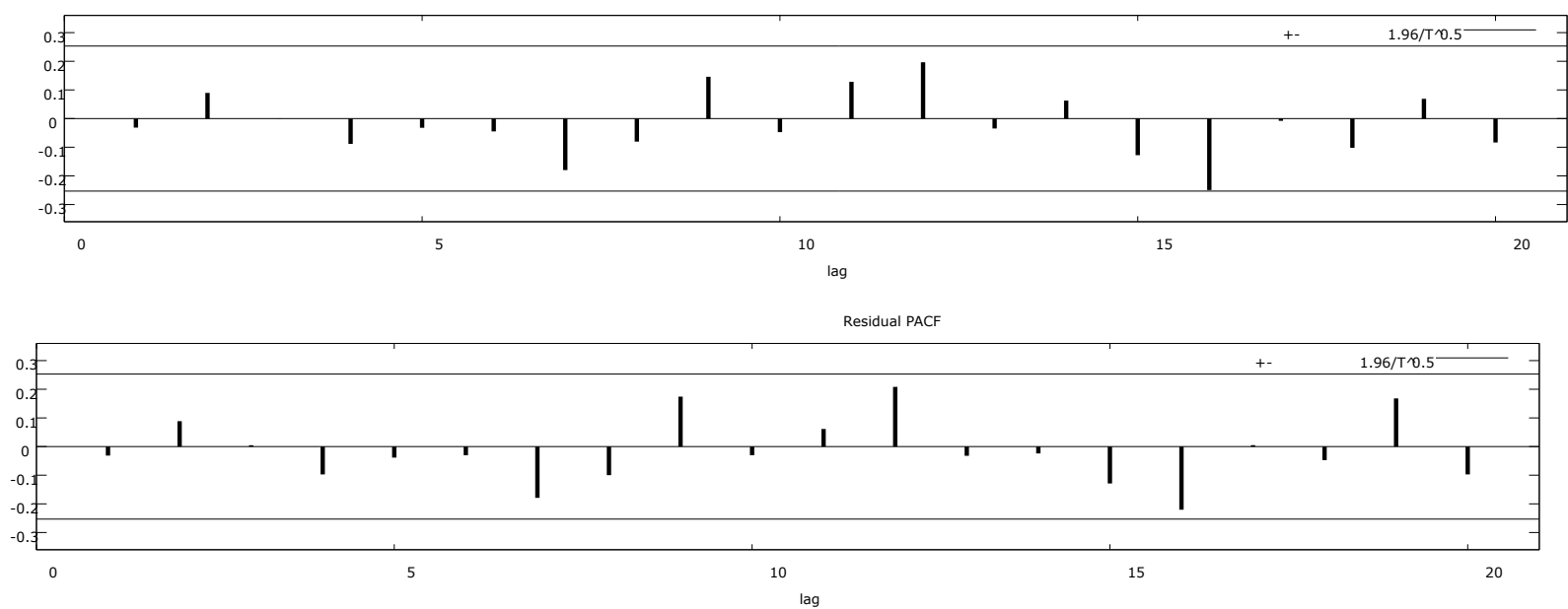

Fig. 3: ACF and PACF of the residuals from deterministic trend with ARMA $(1,0)$ model

If the variances of the disturbances of the level and slope of trend are zero (known as hyper parameters), the structural time series model implies that a deterministic trend is preferable to a stochastic trend. Thus, in the light of these observations, it is hard to conclude on the approach that is better and our view is that both methods are worth using, especially to keep up with further research works in both approaches. However, in time series, it is hard to ascertain whether a single realization contains a trend and to determine whether the trend is deterministic or stochastic.
Also, distinguishing between deterministic and stochastic trends always seems contentious but our study considers a scenario where both the deterministic and stochastic trends coexist in a single realization. To determine whether a trend exists in $X_{t}$, we applied the Augmented Dickey-Fuller test and the result showed that $X_{t}$ is stationary with trend. Hence, the deterministic trend is said to exist in $X_{t}$. We progressed to fit a deterministic trend model to $X_{t}$. Meanwhile, the diagnostic checking indicated the presence of randomness in the residuals of the fitted deterministic trend model 
which is a clear sign that stochastic trend equally exist in $X_{t}$ and such randomness could be modeled by an ARMA $(1,0)$ process. In all, deterministic trend with ARMA $(1,0)$ model was found to be adequate in modeling both the deterministic and stochastic trends in the series.

Moreover, this study could be extended to include the need to model separately the deterministic trend and stochastic trend in $X_{t}$ in order to check which one will perform better.

\section{References}

Caiado J and Crato N (2005). Discrimination between deterministic trend and stochastic trend processes. In the $14^{\text {th }}$ International Conference on Applied Stochastic Models and Data Analysis: 1419-1424. Available online at: https://mpra.ub.uni-muenchen.de/id/eprint/2076

Cryer JD and Chan K (2008). Time series analysis with application in R. Springer, New York, USA.

Dagum EB and Dagum C (2006). Stochastic and deterministic trend models. Statistica, 66(3): 269-280.

Dagum EB and Luati A (2001). A study of the asymmetric and symmetric weights of Kernel smoothers and their spectral properties. Estadistica, 53(160): 215-258.

Dickey DA and Fuller WA (1979). Distribution of the estimators for autoregressive time series with a unit root. Journal of the American Statistical Association, 74(366a): 427-431.

Fuller WA (2009). Introduction to statistical time series. John Wiley and Sons, Hoboken, New Jersey, USA.
Hamilton JD (1994). Time series analysis. Princeton University Press, Princeton, New Jersey, USA.

Harvey AC (1985). Trends and cycles in macroeconomic time series. Journal of Business and Economic Statistics, 3(3): 216227.

MacKinnon JG (1996). Numerical distribution functions for unit root and cointegration tests. Journal of Applied Econometrics, 11(6):601-618.

Moffat IU (2007). On the intervention analysis and robust regression of time series outliers. Unpublished Ph.D. Dissertation, Rivers State University of Science and Technology, Port Harcourt, Nigeria.

Nelson CR and Plosser CR (1982). Trends and random walks in macroeconmic time series: some evidence and implications. Journal of Monetary Economics, 10(2): 139-162.

Qi M and Zhang PG (2008). Trend time series modeling and forecasting with neural network. IEEE Transaction on Neural Networks, 19(15): 808-816.

Rao BB (2010). Deterministic and stochastic trends in the time series models: A guide for the applied economist. Applied Economics, 42(17): 2193-2202.

Said SE and Dickey DA (1984). Testing for unit roots in autoregressive-moving average models of unknown order. Biometrika, 71(3): 599-607.

Watson MW (1986). Univariate detrending methods with stochastic trends. Journal of Monetary Economics, 18(1): 4975 .

Wei WW (2006). Time series analysis: Univariate and multivariate methods. Pearson Addison Wesley, Boston, USA. 